\title{
Low-Cost Rotating Experimentation in Compressor Aerodynamics Using Rapid Prototyping
}

\author{
Mathias Michaud, Petro Jr. Milan, and Huu Duc Vo \\ Department of Mechanical Engineering, École Polytechnique de Montréal, Campus UdeM, 2900 Boulevard Édouard-Montpetit, \\ 2500 Chemin de Polytechnique, Office C318.9, Montréal, QC, Canada H3T 1J4
}

Correspondence should be addressed to Mathias Michaud; mathias.michaud@polymtl.ca

Received 7 November 2015; Revised 8 January 2016; Accepted 20 January 2016

Academic Editor: Jechin Han

Copyright (C) 2016 Mathias Michaud et al. This is an open access article distributed under the Creative Commons Attribution License, which permits unrestricted use, distribution, and reproduction in any medium, provided the original work is properly cited.

\begin{abstract}
With the rapid evolution of additive manufacturing, 3D printed parts are no longer limited to display purposes but can also be used in structural applications. The objective of this paper is to show that $3 \mathrm{D}$ prototyping can be used to produce low-cost rotating turbomachinery rigs capable of carrying out detailed flow measurements that can be used, among other things, for computational fluid dynamics (CFD) code validation. A fully instrumented polymer two-stage axial-mixed flow compressor test rig was designed and fabricated with stereolithography (SLA) technology by a team of undergraduate students as part of a senior-year design course. Experiments were subsequently performed on this rig to obtain both the overall pressure rise characteristics of the compressor and the stagnation pressure distributions downstream of the blade rows for comparison with CFD simulations. In doing so, this work provides a first-of-a-kind assessment of the use of polymer additive technology for low-cost rotating turbomachinery experimentation with detailed measurements.
\end{abstract}

\section{Introduction}

In the last few decades, computational fluid dynamics (CFD) have risen to prominence as an indispensable tool for aerodynamic research and design, particularly in turbomachinery where they provide a detailed flow field for analysis without the large expenses associated with a physical test rig.

Within the field of turbomachinery, the compressor poses the greatest challenge from an aerodynamics stand point. By forcing flow against a pressure gradient, the compressor is prone to boundary layer separation and aerodynamic instabilities that are extremely detrimental to gas turbine engine performance and operability. On a local level, the flow field inside a typical compressor blade passage is highly complex, with three-dimensional flow features such as tip clearance flow, corner separation, and secondary flow, as illustrated in Figure 1. These flow features directly affect the performance and aerodynamic stability of the compressor and by extension the fuel consumption and operability of the gas turbine engine. Thus, it is highly important for both research and design purposes to adequately capture the flow structures. Yet, this task can pose great challenges for CFD codes and in particular Reynolds-Averaged Navier-Stokes (RANS) CFD codes, which will likely remain the most widely used codes in the near future.

The RANS CFD approach has the least computational resource requirements for simulating flow around complex geometries at realistic operating conditions. It does so by using turbulence models that are generally calibrated for simple flows. As a result, for highly complex flows such as those found inside compressors, RANS CFD codes need to be validated with experimental data in order to be used as reliable engineering tools.

Different methods have been used to obtain detailed experimental data in compressors to validate CFD codes. In certain cases, government institutions can carry out experiments on their test rigs and provide publicly available geometry and associated test data with the engineering community for validating CFD codes. For instance, measurements made on NASA Rotor 37 rig using conventional probes and laser Doppler velocimetry (LDV) were used to assess the quality of the solutions of single axial compressor rotor 


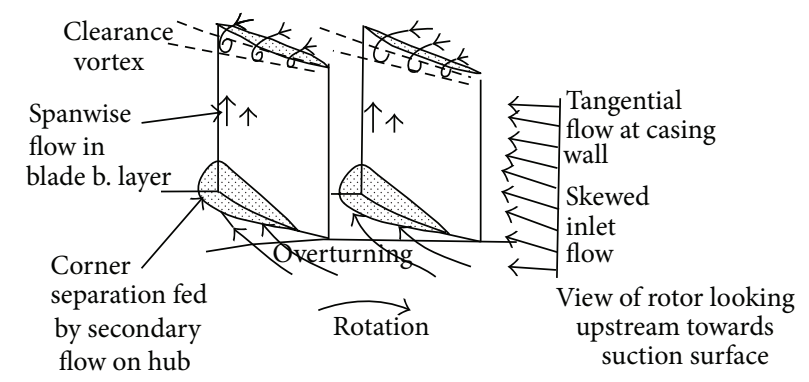

Figure 1: Typical flow structures inside a compressor blade passage [7].

simulations [1-3]. On the other hand, one may choose to use an existing in-house compressor rig to perform new specific tests for code assessment. Van Zante et al. [4] performed tip clearance flow LDV measurements on an existing NASA Rotor 35 to assess the accuracy of numerical tip clearance flow predictions. To validate numerical simulations of more complex compressors, Mansour et al. [5] and Cornelius et al. [6] validated their computational solutions with measurements obtained from their multistage transonic compressor rig.

In either case, one is limited to past compressor geometries, which is the reason for the conservative nature of the aeroengine business as codes validated on past data bases may not be reliable for prediction of significantly different new geometries.

While the ideal solution would be the development of a customized test rig for validation on a specific compressor geometry, this option is traditionally prohibitively expensive both in time and in cost even for industry let alone academia. However, the feasibility of this third option has recently changed drastically with the advent and rapid evolution of additive manufacturing technology, also known as rapid prototyping or $3 \mathrm{D}$ printing.

Additive manufacturing essentially consists of "printing" three-dimensional objects layer by layer. Initially developed over two decades ago for printing plastic objects using lasercured photopolymer (stereolithography or SLA technology), it has evolved into multiple methods with a significant drop in the price of both the machines and the polymer, making it affordable to even hobbyists. Not only is this technology less man-power intensive and wasteful than traditional machining, it also allows for much more complicated parts to be built. The technology has in recent years expanded to printing metallic parts. However, metal 3D printing is still prohibitively expensive and out of reach for the average user.

While the large majority of the polymer printed parts has been for demonstration purposes, some structural applications have been recently added, such as printed remote controlled airplanes and drones. In 2011, a yearly twosemester team design project in turbomachinery described by Vo and Trepanier [8] was introduced at École Polytechnique de Montréal in fulfilment of a design requirement in the mechanical and aerospace engineering curriculums. The project consisted of designing, using industrial practices, building, and running a fully functional instrumented research compressor test rig, including a two-stage compressor made in polymer using rapid prototyping, at cost of about CAD $\$ 15,000$, excluding the reusable electric motor and controller. The compressor would rotate up to 7200 RPM and have a tip speed up to Mach 0.25 . In doing so, the plastic compressor design provided similar structural challenges, such as blade deformation under rotation, to metal compressor operating at higher speeds. Aside from the engineering training intent, Vo and Trepanier [8] wanted to see if a low-cost compressor test rig could be built for research. Over the first three years of the project, the compressor rigs designed and built in this project evolved in functionality and complexity. The second-year (2012-2013) rig was an axial-centrifugal compressor rig successfully used to test a casing plasma actuation concept for delaying aerodynamic instabilities [9]. The third-year (2013-2014) rig incorporated an axial stage with complex blade geometries followed by a seldom used mixed flow stage. It also featured multiple $1 \mathrm{D}$ and 2D traverse systems for detailed stagnation pressure measurements before and after every blade row for CFD code validation. This paper describes the experiments carried out in this rig to serve as a first formal assessment of the use of rapid prototyping to obtain detailed flow measurements in rotating turbomachinery at low-cost.

\section{Experimental Setup}

Figures 2 and 3 present two views of the two-stage axialmixed flow compressor test rig used in this paper with the various incorporated instrumentation indicated. The rig is driven by $0-8900$ RPM $5.7 \mathrm{~kW}$ Baldor-Reliance AC electric motor and controller. The compressor and instrumentation supports are made by SLA out of photopolymer with the totality of the parts printed in less than two weeks. The rest of the components of the rig (shaft, supports, and plenum) were made from steel through machining. During the tests, a screen was placed on the bellmouth intake, as seen in Figure 3, to prevent foreign object damage (FOD).

The first stage of the compressor incorporated a tapered $177.8 \mathrm{~mm}$ inlet diameter axial rotor with $7.5^{\circ}$ taper angle at the tip, followed by a cantilevered stator with constant hub and tip radii and a hub clearance. The second stage has a mixed flow rotor with blade tip inlet and exit diameters of 156.21 and $215.9 \mathrm{~mm}$, respectively, followed after a vaneless space by a $246.38 \mathrm{~mm}$ (tip) diameter stator with constant hub and shroud radii (no tip nor hub clearance). Figure 4 shows the rig without casing to expose the two rotors. 


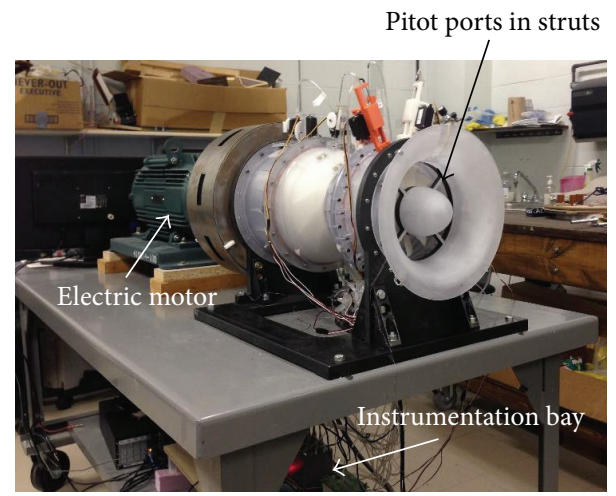

FIGURE 2: Low-speed axial-mixed compressor test rig with instrumentation.

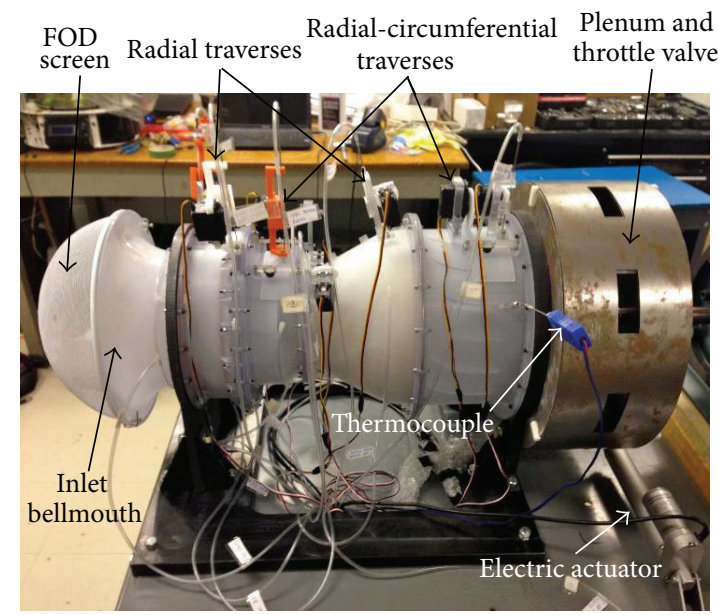

FIGURE 3: Side view of low-speed axial-mixed compressor test rig with instrumentation.

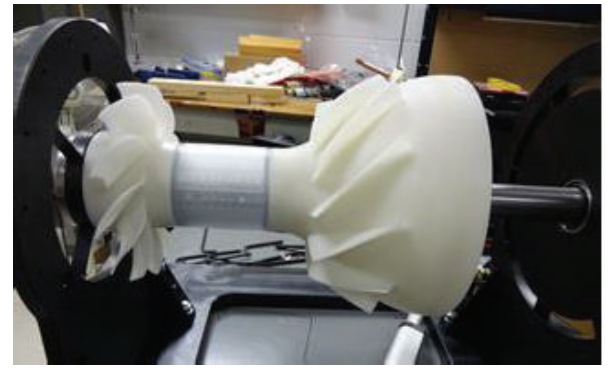

FIGURE 4: Low-speed axial-mixed compressor test rig without casing showing axial and mixed flow rotors.

The compressor was originally designed to operate at a corrected speed $\left(N_{c}\right)$ of 7200 RPM. However, the placement of a cap to repair a hole accidentally drilled through the hub of the mixed flow rotor forced a reduction in the operating mechanical speed to $4450 \mathrm{RPM}$, which corresponds to a corrected speed of $4382 \mathrm{RPM}$ under the ambient temperature of the tests. However, this reduced speed did not prevent the current work from achieving its objective of demonstrating the capability of a 3D printed rotating rig to produce detailed measurements of the flow field. Under the test conditions, the axial rotor has an inlet circumferential tip Mach number and Reynolds number (based on tip chord) of 0.12 and 1.08 $\times 10^{5}$, respectively, while the equivalent values for the mixed flow rotor are 0.11 and $2.02 \times 10^{5}$. Tables 1 and 2 provide the main design characteristics of each stage at both speeds, with the design point at $N_{c}=4382 \mathrm{RPM}$ which corresponds to peak-efficiency conditions at this speed.

As shown in Figure 3, the flow exiting the compressor enters a cylindrical plenum with rectangular holes on its periphery. A concentric cylindrical sleeve with the same hole pattern and actuated by a linear electric actuator slides over the periphery of the plenum to change the alignment of the holes, thus acting as a throttle valve to vary the mass flow. It is noted that the volume of the plenum is sufficiently small such that only rotating stall can occur.

The use of rapid prototyping for much of the geometrically complex parts of the rig helped to minimize the cost of the rig. In this case, these parts came to $\mathrm{CAD} \$ 8,500$. With the costs of steel components and accessories (servos, Kiel probes, bolts, nuts, bearings, and tubes) amounting to CAD $\$ 4,750$ and CAD $\$ 900$, respectively, the total cost of the rig test section was about $\mathrm{CAD} \$ 15,350$. This is a very small fraction of the cost of a similar traditional metallic rig. Furthermore, the use of $3 \mathrm{D}$ printing allows complex 

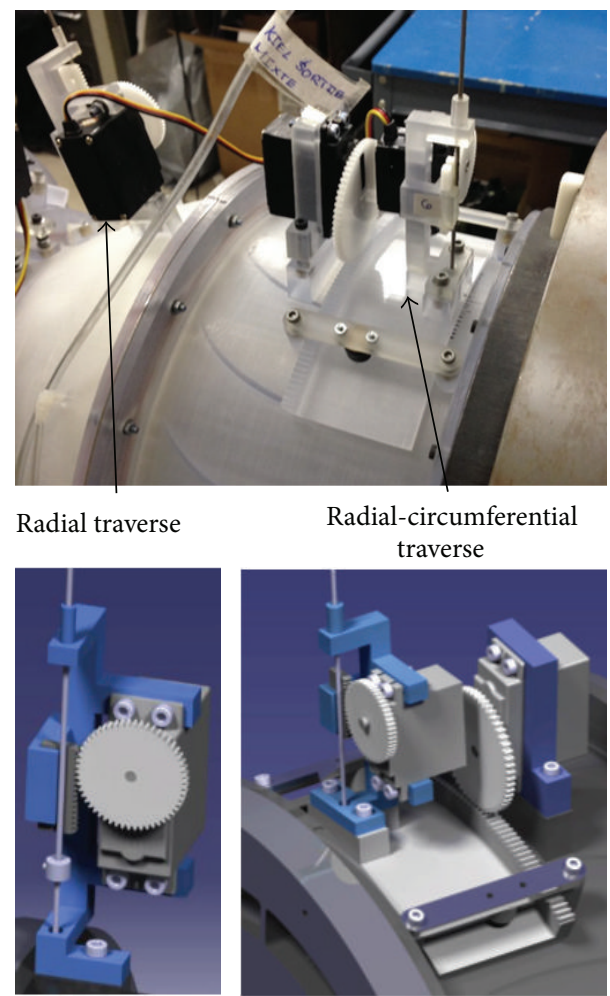

Radial-circumferential traverse

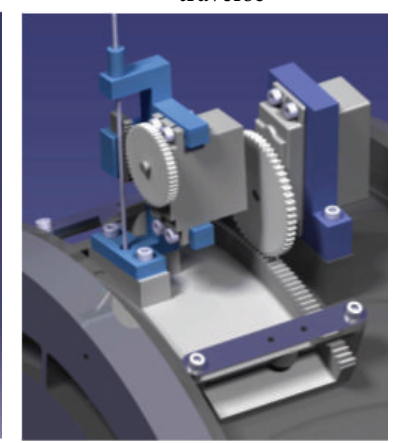

Figure 5: Radial and radial-circumferential traverse designs.

TABLE 1: Design parameters of the axial compressor stage.

\begin{tabular}{lcc}
\hline Parameter & $N_{c}=7200 \mathrm{RPM}$ & $N_{c}=4382 \mathrm{RPM}$ \\
\hline $\begin{array}{l}\text { Design corrected mass flow } \\
\text { (kg/s) }\end{array}$ & 0.511 & 0.330 \\
$\begin{array}{l}\text { Design stagnation pressure } \\
\text { rise coefficient }\end{array}$ & 0.414 & 0.390 \\
$\begin{array}{l}\text { Design efficiency } \\
\text { Rotor inlet circum. tip } \\
\text { speed (m/s) }\end{array}$ & 0.894 & 0.874 \\
$\begin{array}{l}\text { Rotor inlet tip radius (mm) } \\
\text { Rotor inlet hub-tip ratio }\end{array}$ & 65.2 & 41.4 \\
$\begin{array}{l}\text { Rotor tip clearance/stator } \\
\text { hub clearance (mm) }\end{array}$ & \multicolumn{2}{c}{0.488} \\
$\begin{array}{l}\text { Number of blades } \\
\text { (rotor/stator) }\end{array}$ & $0.254 / 0.254$ \\
\hline
\end{tabular}

components to be built in one operation, exemplified by the bellmouth intake with a pitot tube integrated directly into each of its four struts (Figure 2) or the swept and bowed blade shape of the axial rotor (Figure 4).

In terms of instrumentation, the test section incorporates $1.59 \mathrm{~mm}$ diameter Kiel probes from United Sensor ${ }^{\mathrm{Ti}}$ placed on radial traverses downstream of each of the two rotors as well as on radial-circumferential traverses immediately downstream of the two stators. Figure 5 shows a picture of the two types of traverses along with CATIA illustrations of their designs. The traverses are powered by off-the-shelf servos controlled via an Arduino ${ }^{\text {min }}$ board. The accuracy of
TABLE 2: Design parameters of the mixed flow compressor stage.

\begin{tabular}{|c|c|c|}
\hline Parameter & $N_{c}=7200 \mathrm{RPM}$ & $N_{c}=4382 \mathrm{RPM}$ \\
\hline $\begin{array}{l}\text { Design corrected mass flow } \\
(\mathrm{kg} / \mathrm{s})\end{array}$ & 0.511 & 0.330 \\
\hline $\begin{array}{l}\text { Design stagnation pressure } \\
\text { rise coefficient }\end{array}$ & 1.801 & 1.39 \\
\hline Design efficiency & 0.917 & 0.766 \\
\hline $\begin{array}{l}\text { Rotor inlet circum. tip } \\
\text { speed }(\mathrm{m} / \mathrm{s})\end{array}$ & 59.9 & 36.4 \\
\hline Rotor inlet tip radius (mm) & \multicolumn{2}{|c|}{78.2} \\
\hline Rotor inlet hub-tip ratio & \multicolumn{2}{|c|}{0.600} \\
\hline $\begin{array}{l}\text { Rotor outlet tip radius } \\
(\mathrm{mm})\end{array}$ & \multicolumn{2}{|c|}{109} \\
\hline Rotor outlet hub-tip ratio & \multicolumn{2}{|c|}{0.902} \\
\hline Stator inlet tip radius $(\mathrm{mm})$ & \multicolumn{2}{|c|}{123} \\
\hline Stator inlet hub-tip ratio & \multicolumn{2}{|c|}{0.886} \\
\hline $\begin{array}{l}\text { Rotor tip clearance/stator } \\
\text { hub clearance }(\mathrm{mm})\end{array}$ & \multicolumn{2}{|c|}{$0.381 / 0$} \\
\hline $\begin{array}{l}\text { Number of blades } \\
\text { (rotor/stator) }\end{array}$ & \multicolumn{2}{|c|}{$11 / 17$} \\
\hline
\end{tabular}

the traverses is $0.254 \mathrm{~mm}$ in the radial direction and $0.2^{\circ}$ in the circumferential direction. At the exit of each blade row, four static pressure ports (one per quadrant, placed at 0,25 , 50 , and $75 \%$ pitch of the nearest stator blade passage) are placed on the casing. They are connected together to obtain an average casing static pressure for each station.

The rig also features ports with threaded metal inserts to incorporate dynamic pressure Kulite $e^{\text {tw }}$ probes and optical tip clearance probes. Unfortunately, at the reduced rotating speed of the tests, the stall pressure perturbations were small enough to fall within the noise of the Kulite probes on hand initially purchased for a high-speed compressor. In addition, the optical tip clearance probes did not work well with the light color of the rotor blades. Consequently, these probes were not used in the tests. However, these two problems can be overcome with higher operating speeds (and/or dynamic pressure sensors with lower-range) and darker rotor blades.

Other instrumentation includes AOSONG ${ }^{\mathrm{mm}}$ AM2301 sensor, which measures ambient pressure and relative humidity as well as calibrated high-precision thermocouple for ambient (inlet) air temperature. A similar thermocouple is placed downstream of the last stator to measure the exit flow temperature. However, this last thermocouple was not used in the present experiments because the temperature rise associated with the reduced operating speed is not sufficiently high compared to the calibrated accuracy of the two thermocouples for a reasonable error margin in efficiency measurement. In addition, a tachometer integrated with the motor controller provides the mechanical rotational speed $(N)$. Last but not least, a thermocouple is installed on the outer race of each of the two bearings to monitor their temperatures. All thermocouples were of type $\mathrm{K}$.

Figure 6 presents a cross section of the compressor with the instrumentation used in this study. As mentioned earlier, the static pressure $\left(P_{S}\right)$ at each station was taken at the shroud 
TABLE 3: Summary of rig instrumentation used in the study.

\begin{tabular}{|c|c|c|c|c|}
\hline$P_{\mathrm{amb}}$ & $T_{\mathrm{amb}}$ & $P_{T 1}$ & $P_{S 1}$ & $P_{T 3}$ \\
\hline Ambient pressure & $\begin{array}{c}\text { Ambient } \\
\text { temperature }\end{array}$ & $\begin{array}{c}\text { Stagnation } \\
\text { pressure at } \\
\text { bellmouth outlet } \\
\text { struts (midspan) }\end{array}$ & $\begin{array}{l}\text { Static pressure on } \\
\text { shroud at } \\
\text { bellmouth outlet }\end{array}$ & $\begin{array}{l}\text { Stagnation pressure at } \\
\text { axial rotor exit }(0.91 \\
\text { axial tip chord } \\
\text { downstream of rotor } \\
\text { tip TE) }\end{array}$ \\
\hline$P_{T 4}$ & $P_{S 4}$ & $P_{T 6}$ & $P_{T 7}$ & $P_{S 7}$ \\
\hline $\begin{array}{l}\text { Stagnation } \\
\text { pressure at axial } \\
\text { stator exit }(0.45 \\
\text { axial tip chord } \\
\text { downstream of } \\
\text { stator tip TE) }\end{array}$ & $\begin{array}{c}\text { Static pressure on } \\
\text { shroud at axial } \\
\text { stator exit }(0.39 \\
\text { axial chord } \\
\text { downstream of } \\
\text { stator tip TE })\end{array}$ & $\begin{array}{c}\text { Stagnation } \\
\text { pressure at mixed } \\
\text { flow rotor exit } \\
(0.33 \text { axial tip } \\
\text { chord downstream } \\
\text { of rotor tip TE })\end{array}$ & $\begin{array}{c}\text { Stagnation } \\
\text { pressure at mixed } \\
\text { flow stator exit } \\
(0.29 \text { axial tip } \\
\text { chord downstream } \\
\text { of stator tip TE) }\end{array}$ & $\begin{array}{l}\text { Static pressure on } \\
\text { shroud at mixed flow } \\
\text { stator exit }(0.39 \text { axial } \\
\text { chord downstream of } \\
\text { stator tip TE) }\end{array}$ \\
\hline
\end{tabular}

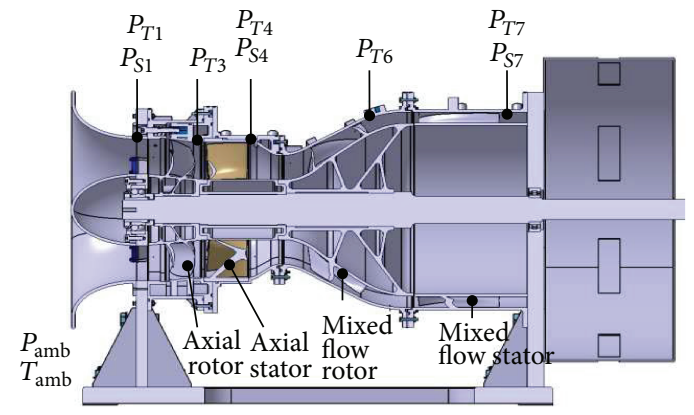

FIGURE 6: Cross section of compressor test rig with instrumentation used in the study.

and averaged over four quadrants. With the exception of $P_{T 1}$ which was averaged from a midspan hole in each of the four intake struts, the stagnation pressure $\left(P_{T}\right)$ is obtained from Kiel probes on radial (downstream of rotors) or radialcircumferential (downstream of stators) traverses. Table 3 summarizes the location of the instrumentation used in this study. A discharge coefficient correlation of the bellmouth had been determined by the rig designers through CFD simulations such that the mass flow $(\dot{m})$ can be obtained from $P_{T 1}$ and $P_{S 1}$ measurements. With the presence of a screen in front of the intake during the tests to avoid foreign object damage (FOD screen in Figure 3), $P_{T 1}$ and $T_{\text {amb }}$ are the compressor inlet conditions used for correcting the mass flow $\left(\dot{m}_{c}\right)$ and rotational speed $\left(N_{c}\right)$. These inlet conditions are also used along with the ambient humidity measurement for calculating the density $(\rho)$ needed to obtain the pressure rise coefficients $\Psi_{T S}$ and $\Psi_{T}$. The stagnation-to-static pressure rise is calculated using $P_{S 4}$ and $P_{S 7}$ for the exit static pressure of the axial stage and the entire two-stage compressor, respectively. $P_{T 3}$ and $P_{T 6}$ measurements from Kiel probes mounted on radial traverses are used to obtain the radial distributions of stagnation pressure at the exit of the axial and mixed flow rotors, respectively. Similarly, $P_{T 4}$ and $P_{T 7}$ measurements from Kiel probes on radial-circumferential traverses provide the $2 \mathrm{D}$ contours of stagnation pressure at the outlet of the axial and mixed flow stages, respectively. Apart from $P_{\mathrm{amb}}$, all of the pressure measurements were made relative to $P_{\text {amb }}$ using a NetScanner 9116 system with sixteen $6895 \mathrm{~Pa}$ piezoelectric gauge pressure transducers each having an accuracy of $\pm 6.895 \mathrm{~Pa}$.

With the Kulite probes ineffective at the tested speed, rotating stall was detected using a visual method. This method consisted of hanging a thin string from the shroud just upstream of the axial rotor. In stable operation, this string would point downstream. Once in rotating stall, this string would oscillate back and forth. However, the rotating stall was also correlated with a drop in stagnation-to-static pressure rise coefficient and large increase in mass flow oscillations amplitude. Similarly, since the optical tip clearance probes were not working properly, the tip and hub clearance were obtained at rest using filler gauge measurements at the leading edge and trailing edge around the annulus for each relevant blade row and averaged separately for the leading and trailing edges. The reductions in rotor tip clearances due to blade deformation under rotation were obtained by finite element analysis with ANSYS Mechanical ${ }^{\mathrm{Tw}}$ (Version 14.5).

The test procedure consisted of first obtaining the stagnation-to-static pressure rise characteristics (speedline). This was done by closing the throttle from a fully open position in steps until rotating stall occurs. At every throttle position, 30 seconds of pressure data was taken at a sampling rate of $250 \mathrm{~Hz}$ but only the last 10 seconds of data was averaged for calculating $\Psi_{T S}$ and $\dot{m}_{c}$. This corresponds to a settling time of 20 seconds, which is about 400 flow convection times across the compressor. Subsequently, the throttle is set to the position of the peak-efficiency point for stagnation pressure profile/contours measurements. For the radial stagnation pressure profiles at the exit of the axial and mixed flow rotors, 37 and 12 points, respectively, are taken from hub to shroud at $1.27 \mathrm{~mm}$ intervals. For the pressure contours at the exit of the stators, points were taken at $2.54 \mathrm{~mm}$ radial and $1^{\circ}$ circumferential intervals to cover just above one-blade pitch. This resulted in 18 radial by 32 circumferential positions ( 576 points) for the axial stator and 6 radial by 26 circumferential positions (156 points) for the mixed flow stator. For each measurement point, one second of data at $250 \mathrm{~Hz}$ pressure sampling rate is taken after a settling time of 2 seconds (about 40 flow convection times) following each displacement of the Kiel probe. The acquisition of the stagnation pressure 


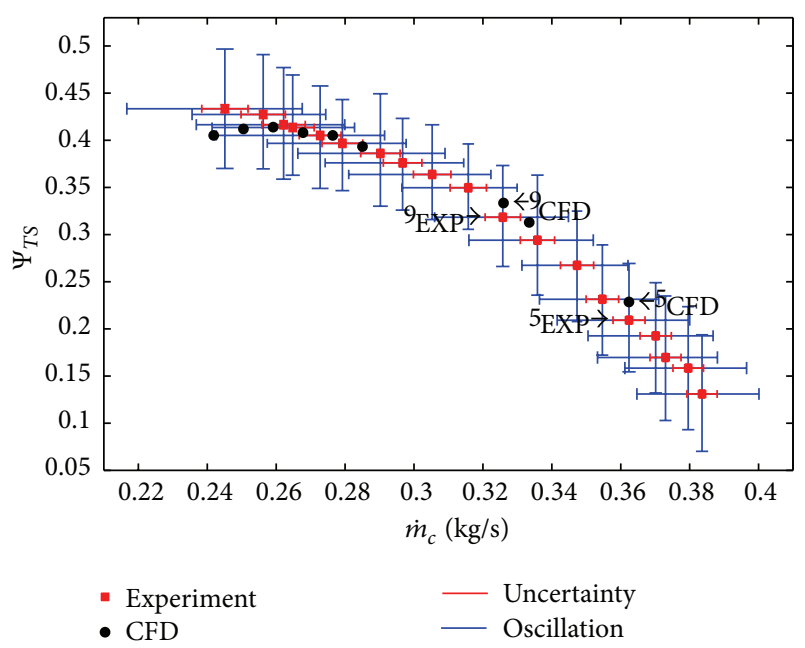

FIGURE 7: Measured versus computational stagnation-to-static pressure rise characteristic for the axial stage.

contours downstream of the stators took about 45 minutes with the rig running in steady state.

In terms of the operation of the rig itself, it has so far been run for a total of about 10 hours without any sign of wear. For the experiments described in this paper, the data was acquired over a period of two hours. During these two hours of operation, the test rig was running smoothly with very low vibrations. The temperatures of its two bearings, which were monitored with thermocouples placed on their outer race, stabilized at $2^{\circ} \mathrm{C}$ above rest value and remained below $26^{\circ} \mathrm{C}$, which is well below the softening temperature of any polymer component in the rig. All the displacements of the traverses were smooth. Thus, the signs so far on this rig do not point to any operational issue associated with using 3D printed polymer compressor rigs for research for which the frequency of usage is also much less than an industrial rig.

\section{Results and Discussion}

This section presents the experimental results. Since corresponding computational results from CFD validation exercise are also available, they are shown alongside as a complement to give an idea of the usefulness of the test data and also to point out certain aspects to consider with $3 \mathrm{D}$ printed rotating test rigs. It is noted that CFD simulations of the flow in the entire compressor were carried out using the deformed axial rotor blade at the new mechanical rotating speed of 4450 RPM while blade deformation for the mixed flow rotor, which was found to be an order of magnitude lower, was neglected for simplicity. The details on the computational setup and postprocessing of the CFD data are described in the Appendix.

Figures 7 and 8 present the general performance data in terms of the measured versus computational stagnation-tostatic rise characteristic for the axial stage and the two stages combined. The test data includes both the error margins from the instruments (which for $\Psi_{T S}$ is smaller than the symbol

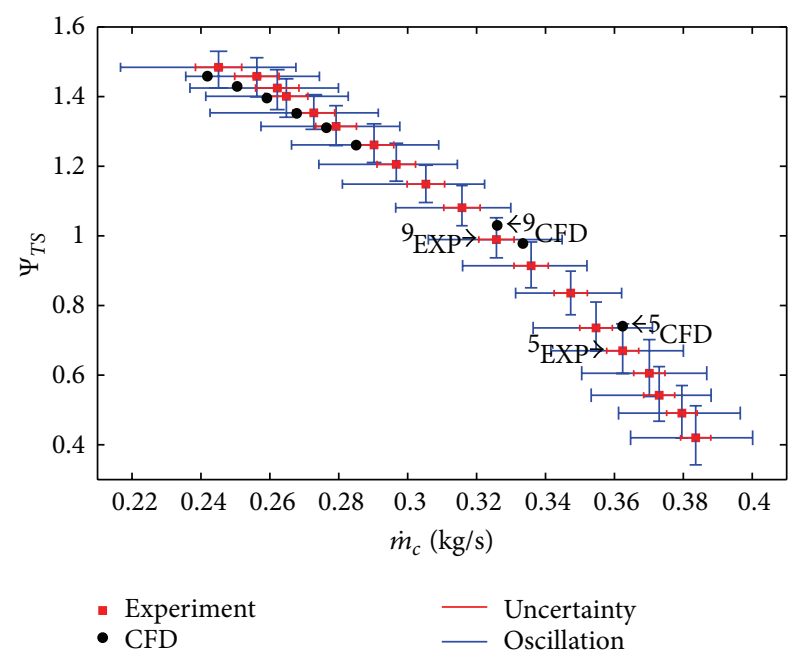

FIGURE 8: Measured versus computational stagnation-to-static pressure rise characteristic for both stages combined.

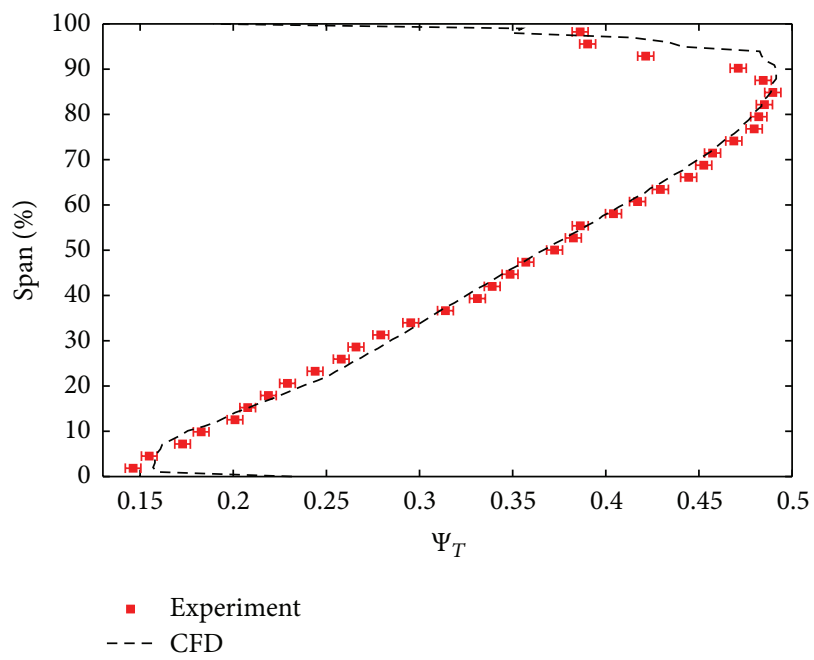

Figure 9: Comparison of measured versus predicted spanwise distribution of nondimensional stagnation pressure downstream of the axial rotor at point 9 in Figure 7.

size) and the margins corresponding to the flow oscillation amplitude in mass flow and pressure. The last point on each curve represents the last stable point before compressor stall (rotating stall) occurs. This is the most common type of test data used for validation but only on the general level. In this case, these test results were used to show that the numerical setup captures both the shape and stall point of the speedline well for both the first stage and the entire compressor.

For a more detailed investigation of the flow field at the peak-efficiency point (point 9 in Figure 7), Figure 9 plots the measured versus predicted stagnation pressure profile just downstream of the axial rotor while Figure 10 compares the experimental versus simulated stagnation pressure contours at the exit of the axial stator. Figures 11 and 12 present the equivalent plots for the mixed flow stage. It is noted that, in Figure 9, the error margin in span position is smaller than 


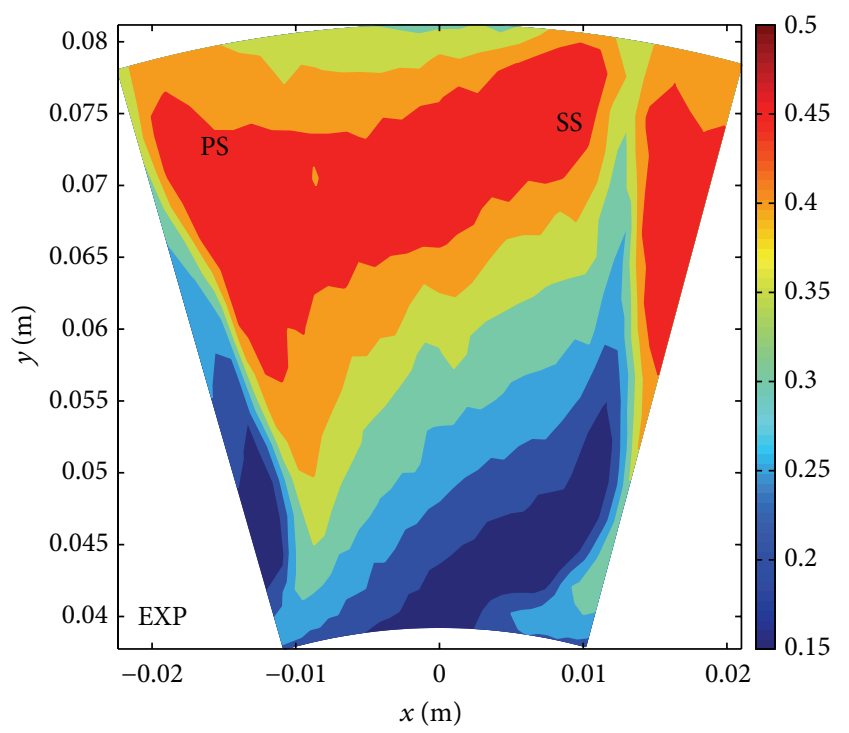

(a)

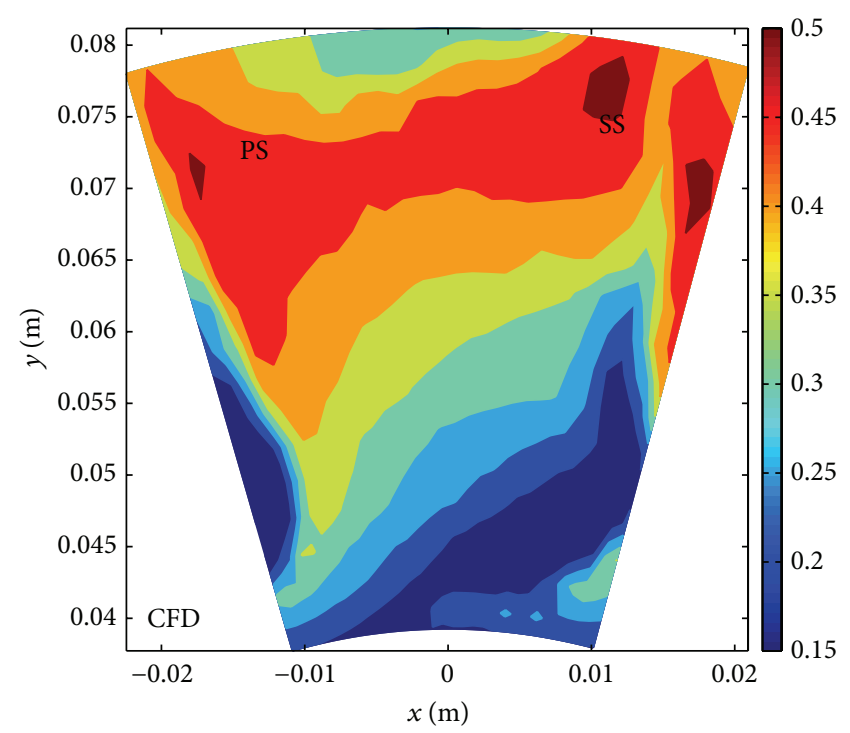

(b)

FIGURE 10: Comparison of measured (a) versus predicted (b) nondimensional stagnation pressure contours downstream of the axial stator over 1.12-blade pitch at point 9 in Figure 7.

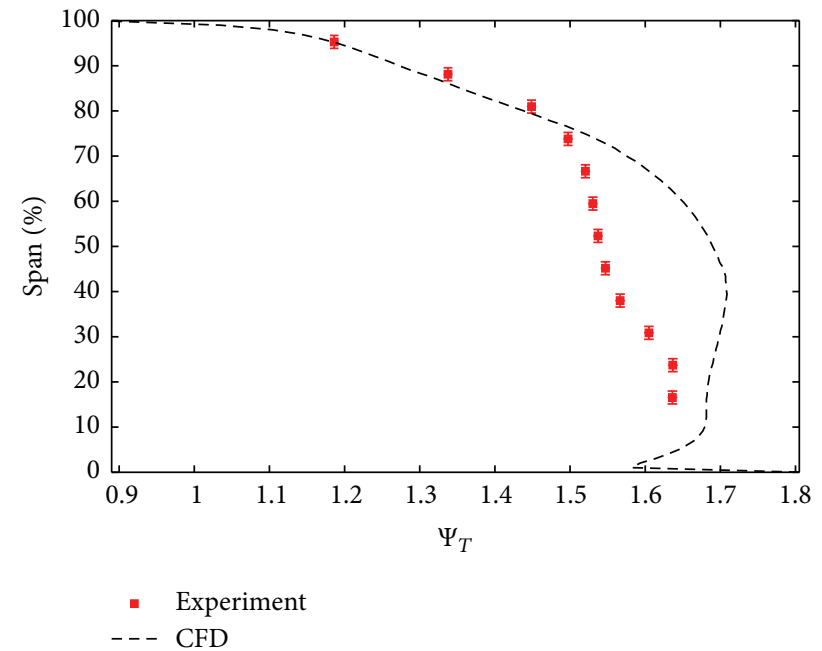

FIGURE 11: Comparison of measured versus predicted spanwise distribution of nondimensional stagnation pressure downstream of the mixed flow rotor at point 9 in Figure 7.

the symbols whereas, in Figure 11, the error margin on the stagnation pressure is smaller than the symbols. The good concordance of the test data with numerical predictions in Figures 9 and 10 for the axial stage is an indication that the experimental setup works very well in delivering the same type of data that has until now only been possible to obtain with much more expensive rotating test rigs.

At the same time, the lesser agreement between test data and CFD predictions for the mixed flow stage (Figures 11 and 12) indicates that the numerical setup may require some refinements to better capture the local flow phenomena in this rear stage. For example, the use of several mixing plane interfaces (see the Appendix) that circumferentially average the flow properties from one computational subdomain to another reduces the numerical accuracy as one moves towards the rear stages in a multistage compressor simulation. Moreover, the flow in nonaxial compressor geometries is more complex and harder to predict accurately with CFD codes.

Aside from numerical considerations, the differences between test data and CFD predictions for the mixed flow stage also expose certain aspects that need to be considered in $3 \mathrm{D}$ printed rotating rigs. First, while the simulations assume circumferentially uniform tip/hub clearances, it was found that the tip clearances in the test compressor varied circumferentially by up to $\pm 17 \%$ for both the axial and mixed flow rotors. Indeed, the precision of $3 \mathrm{D}$ printing is less than machining and will depend on the type of 3D printer used. As such, some postprocessing of the part may be required to ensure dimensional accuracy. In the case of a polymer rig, this can be carried out relatively quickly at low-costs through careful sanding. Second, even under modest rotational speed, a polymer rotor blade may have deformation significant enough to change the performance. It is thus important to take this fact into account when designing these rotors so that their manufactured geometry will deform under rotation to the desired form at design conditions. Furthermore, if the rig runs at a different rotational speeds, the revised rotor shapes must be taken into account in CFD simulations. In this study, the shape revision was done for the axial rotor but not for the mixed flow rotor for the reason mentioned earlier, even if the results may have been slightly better if the relatively small mixed flow rotor deformation has been taken into consideration. However, the issue of blade deformation under rotation is not specific to plastic compressors as metallic compressors of similar size which rotate at higher speeds 


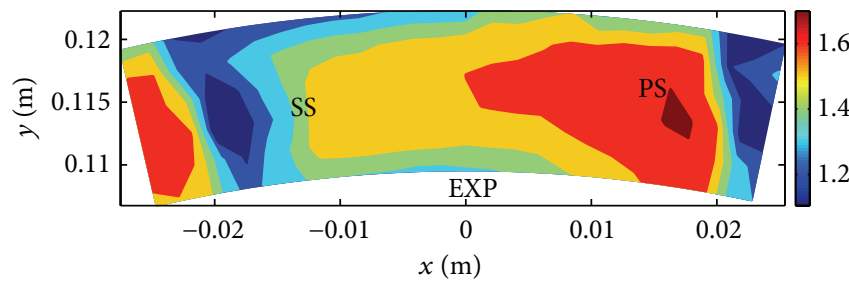

(a)

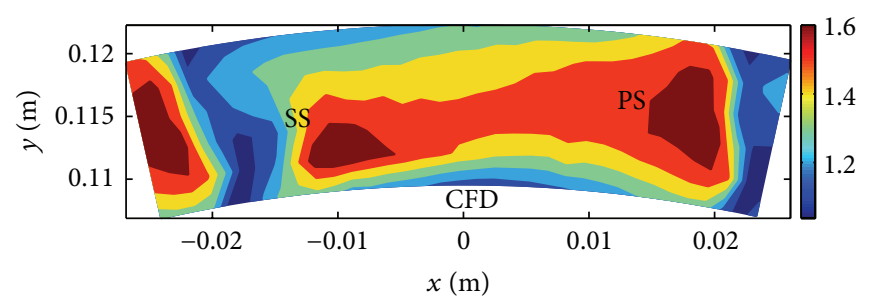

(b)

FIGURE 12: Comparison of measured (a) versus predicted (b) nondimensional stagnation pressure contours downstream of the mixed flow stator over 1.18-blade pitch at point 9 in Figure 7.

would experience similar deformations that must be taken into account in CFD simulations.

Overall, the results show that this low-cost compressor rig in polymer made from rapid prototyping was able to produce very detailed measurements, which can be used for, among other things, a more precise validation of a computational setup for CFD simulations of multistage compressors. If the rig had been able to operate at its intended speed, its circumferential tip Mach number would be around Mach 0.2 , rivaling many low-speed metal compressor rigs that are much more time-consuming and expensive to build, modify, and operate. At this speed, more of the intended instrumentation for the rig may have been operational, thus increasing its capability.

Although the constraints in material strength and temperature of polymer compressor test rigs limit their operation to the lower ranges of compressor rigs in terms of speed and pressure rise, they are still highly useful in exploring the flow physics and new blading concepts at a cost that is unrivalled by any existing metallic compressors.

\section{Conclusion}

This study showed that a custom rotating compressor rig can be built rapidly and at low-cost for experimentation in turbomachinery with measurements capabilities that rival most traditional metallic compressor test rigs, be it for providing detailed data to validate CFD simulations or to evaluate new blading concepts. This method for building compressor test rigs would provide an invaluable experimental research tool for academia where funds are more limited relative to industry or large research institutions.

\section{Appendix}

\section{Computational Setup}

The computational data shown in CFD simulations were carried out using ANSYS CFX ${ }^{\text {wi }}$ (Version 14.5), a commercial finite-volume Reynolds-Averaged-Navier-Stokes (RANS) CFD code often used for turbomachinery. For the present two-stage compressor, the computational domain was divided into five subdomains, namely, intake, axial rotor, axial stator, mixed flow rotor, and mixed flow stator, as shown in Figure 13. The bellmouth is modeled by a duct of constant

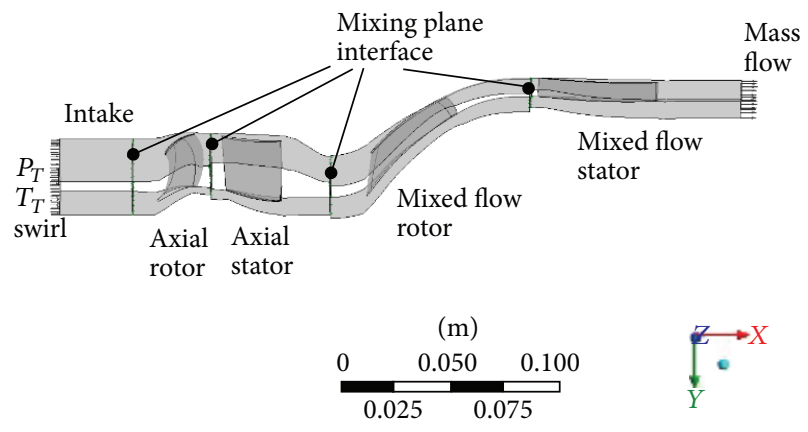

FIGURE 13: Computational domain for two-stage compressor.

hub and tip radii (intake subdomain) with a length equal to $60 \%$ of that of the physical bellmouth. The circumferential width of each subdomain is one-blade pitch, with the intake subdomain taking the width of the axial rotor subdomain. This is made possible by the use of a mixing plane interface between the subdomains.

As shown in Figure 13, the inlet conditions to the computational domain consist of specified values of stagnation pressure and stagnation temperature (uniform) as well as the swirl angle (zero in this case). The exit boundary condition for the computational domain is a specified value of mass flow. All solid surfaces are modeled as a no-slip wall with a surface roughness of $0.00762 \mathrm{~mm}$ for the blade surfaces of the two rotors and $0.0254 \mathrm{~mm}$ for the rest as prescribed by the rig designers. The axial rotor and mixed flow rotor subdomains are solved in the rotating frame while the other subdomains are solved in the stationary frame. As a result, the stationary shroud surface in the rotor subdomains is defined as a counterrotating no-slip surface while the hub of the axial stator subdomain is defined as rotating no-slip surface.

The subdomains were meshed using the turbomachinery meshing software ANSYS TurboGrid ${ }^{\text {TM }}$ (Version 14.5). Each blade is meshed with $\mathrm{O}$-grid surrounded by H-grid. Following a mesh study, the final chosen mesh contained 10,418,860 nodes. The node distributions (meridional $\times$ pitch $\times$ radial) for the intake duct, axial rotor, axial stator, mixed flow rotor, and mixed flow stator subdomains were, respectively, $19 \times 59$ $\times 84,139 \times 59 \times 84,182 \times 52 \times 100,184 \times 39 \times 156$, and $242 \times$ $46 \times 61$ (excluding the O-grid). Figures 14 and 15 show part of the mesh for the axial and mixed flow rotors. The numbers of radial nodes in the tip/hub clearance for the axial rotor 


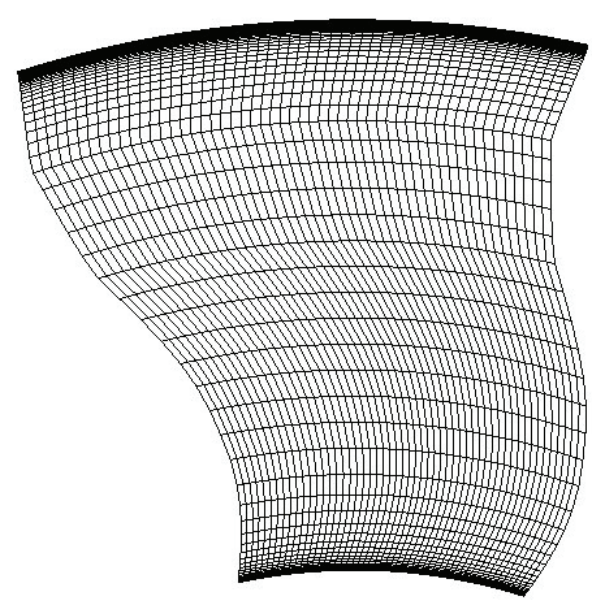

Figure 14: Axial cut of computational mesh for the axial rotor subdomain.

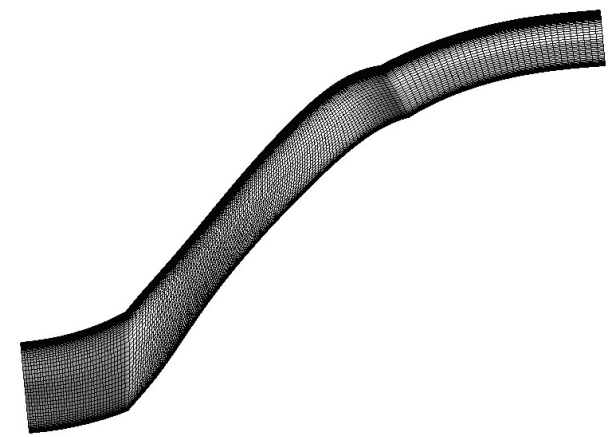

FIGURE 15: Meridional view of the computational mesh for the mixed flow rotor subdomain.

(max. tip clearance of $1.09 \%$ tip chord), axial stator (max. hub clearance of $1.62 \%$ hub chord), and mixed flow rotor (max. tip clearance of $1.28 \%$ tip chord) were, respectively, 24, 38, and 96, all of which surpass the criterion proposed by Van Zante et al. [4] for adequate capture of tip clearance flow. $y+$ value at the solid surfaces goes from below 1 up to 6 .

The SST turbulence model was used along with $\gamma-\theta$ transition model to capture boundary layer transition, given the relatively low Reynolds numbers involved. All simulations were carried out in steady state mode.

The simulation procedure for obtaining points along the speedline consists of getting a first converged solution at a large exit mass flow value. Using this solution at the initial guess, the value of the specified exit mass flow is reduced to obtain the next converged solution up the speedline. This procedure is repeated until the pressure rise suddenly drops, indicating compressor stall. The previous point is then considered the stall (last stable) point. The static pressure value at each relevant station for calculating $\Psi_{T S}$ is obtained by pitch-averaging the value at the shroud.

The mesh was then simulated at the peak-efficiency corrected mass flow such that a back-to-back comparison of the predicted versus stagnation pressure profiles and contours can be carried out. Downstream of each rotor, the stagnation pressure at each span position along the corresponding path of the radial traverse is line-averaged across the blade pitch to obtain the spanwise stagnation pressure profile. For the pressure contours at the exit of the stators, the predicted stagnation pressure at each corresponding measurement point is obtained through a 2D interpolation from the CFD data in order to produce predicted stagnation pressure contours that can be directly compared to those drawn from test data.

\section{Nomenclature}

$N$ : Mechanical compressor rotational speed

$N_{c}$ : Corrected compressor rotational speed $N_{c}=N / \sqrt{T_{t, \text { in }} / \text { Tref }}$

$P_{S}:$ Static pressure

$P_{T}$ : Stagnation pressure

$\rho:$ Density

$U: \quad$ Circumferential tip speed

$\dot{m}:$ Mass flow rate

$\dot{m}_{c}$ : Corrected mass flow rate $\dot{m}_{c}=\left(\dot{m} \sqrt{T_{t, \text { in }} / \text { Tref }}\right) /\left(P_{t, \text { in }} /\right.$ Pref $)$

$\Psi_{T S}$ : Stagnation-to-static pressure rise coefficient $\Psi_{T S}=\left(P_{s, \text { out }}-P_{T, \text { in }}\right) /(1 / 2) \rho U^{2}$

$\Psi_{T}$ : Stagnation pressure rise coefficient $\Psi_{T}=\left(P_{T, \text { out }}-P_{T, \text { in }}\right) /(1 / 2) \rho U^{2}$.

\section{Conflict of Interests}

The authors declare that there is no conflict of interests regarding the publication of this paper.

\section{Acknowledgments}

The authors would first like to thank the participants in the 2013-2014 team design project that built the compressor rig used in this study, particularly the 17 undergraduate students in the design team for their effort and dedication, as well as for some of the graphical material in this paper. They are also grateful to the government of Québec and BPR Inc. for financing the design project that produced this rig. The research in the current paper was funded by the Natural Sciences and Engineering Research Council of Canada (NSERC) Discovery Grant program for which the authors are grateful. Some of the computations were made on the supercomputer Briarée from Université de Montréal, managed by Calcul Québec and Compute Canada. The operation of this supercomputer is funded by the Canada Foundation for Innovation (CFI), Ministère de l'Économie, de l'Innovation et des Exportations du Québec (MEIE), RMGA, and the Fonds de recherche du Québec-Nature et technologies (FRQ-NT).

\section{References}

[1] J. Dunham and G. Meauzé, "An AGARD working group study of 3D Navier-Stokes codes applied to single turbomachinery blade rows," in Proceedings of the ASME International Gas Turbine and Aeroengine Congress and Exhibition, ASME Paper Paper no. 98GT-050, Stockholm, Sweden, June 1998. 
[2] AGARD, CFD Validation for Propulsion System Components, AGARD-AR-355, AGARD, Neuilly-sur-Seine, France, 1998, edited by: J. Dunham.

[3] R. Biollo and E. Benini, "Validation of a Navier-Stokes solver for CFD computations of transonic compressors," in Proceedings of the 8th Biennial ASME Conference on Engineering Systems Design and Analysis (ESDA '06), vol. 1, pp. 507-514, Torino, Italy, July 2006.

[4] D. E. Van Zante, A. J. Strazisar, J. R. Wood, M. D. Hathaway, and T. H. Okiishi, "Recommendations for achieving accurate numerical simulation of tip clearance flows in transonic compressor rotors," Journal of Turbomachinery, vol. 122, no. 4, pp. 733-742, 2000.

[5] M. L. Mansour, G. Holbrook, J. Gunaraj, M. Qizar, and V. Mangat, "Validation and calibration of modern CFD RANS codes for the prediction of transonic axial-centrifugal compressors," in Proceedings of the ASME Turbo Expo: Power for Land, Sea, and Air, pp. 385-392, Berlin, Germany, June 2008.

[6] C. Cornelius, T. Biesinger, P. Galpin, and A. Braune, "Experimental and computational analysis of a multistage axial compressor including stall prediction by steady and transient CFD methods," Journal of Turbomachinery, vol. 136, no. 6, Article ID 061013, 12 pages, 2014.

[7] N. A. Cumpsty, Compressor Aerodynamics, Longman Scientific \& Technical, London, UK, 1989.

[8] H. D. Vo and J. Y. Trepanier, "Undergraduate project in compressor rig design, fabrication and testing for complete engineering training," in Proceedings of the ASME Turbo Expo 2015: Power for Land, Sea and Air, Paper GT2015-43039, Montreal, Canada, June 2015.

[9] F. Ashrafi, M. Michaud, and H. D. Vo, "Delay of rotating stall in compressors using plasma actuators," in Proceedings of the ASME Turbo Expo: Turbine Technical Conference and Exposition, ASME Paper no. GT2015-42559, Montreal, Canada, June 2015. 


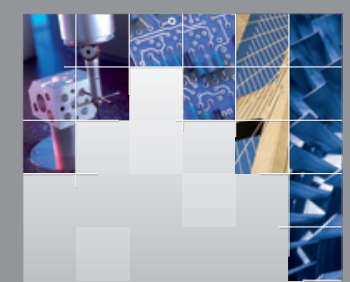

\section{Enfincering}
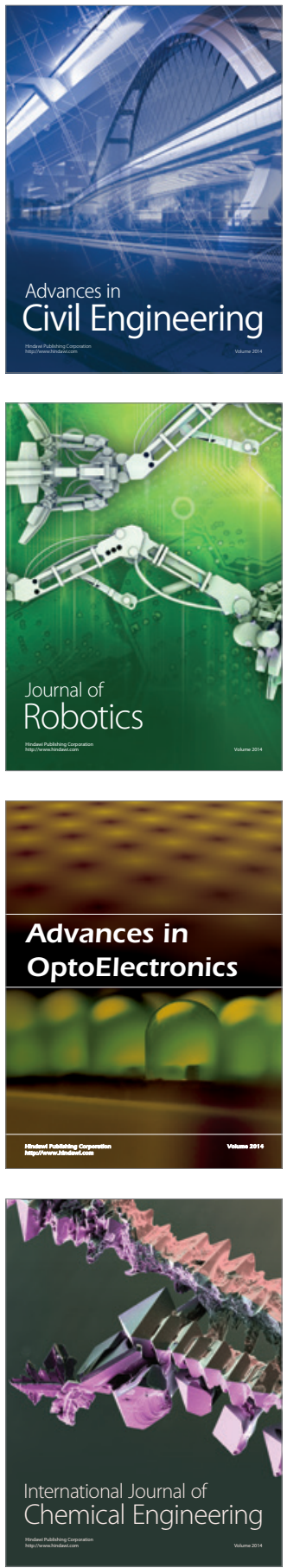

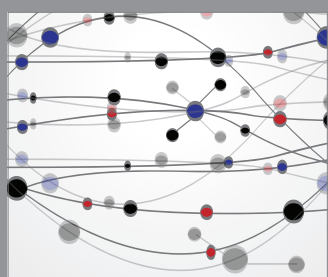

The Scientific World Journal

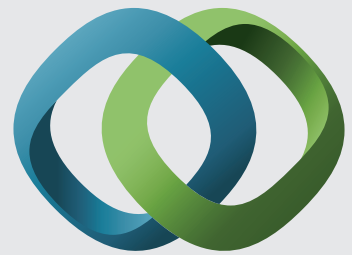

\section{Hindawi}

Submit your manuscripts at

http://www.hindawi.com
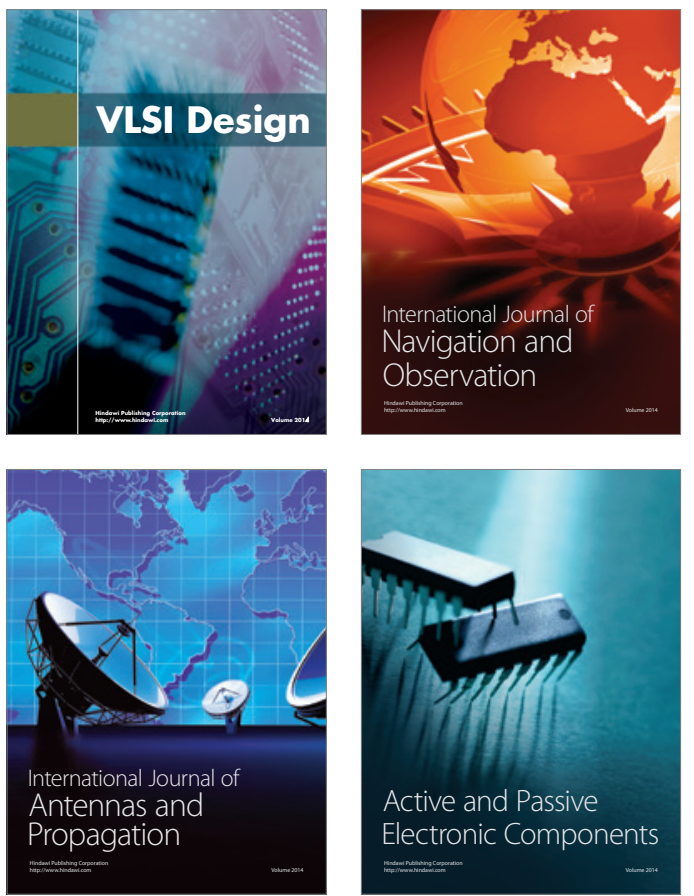
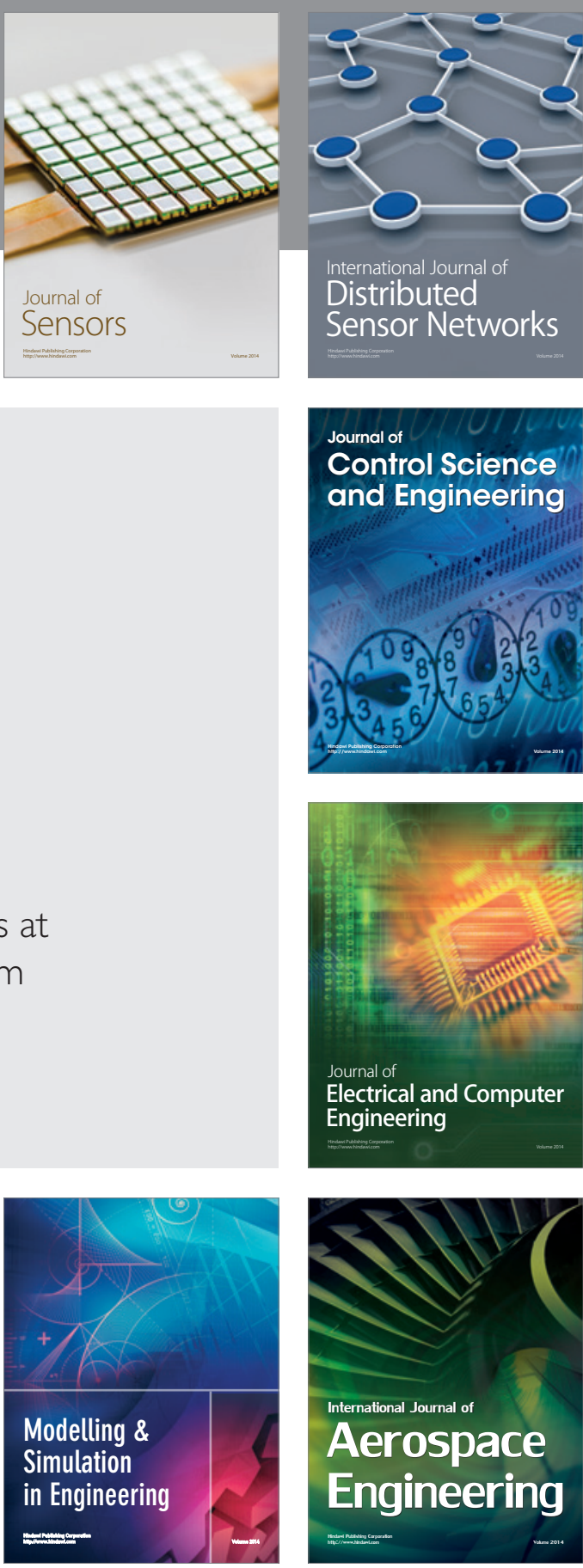

International Journal of

Distributed

Sensor Networks

Journal of

Control Science

and Engineering
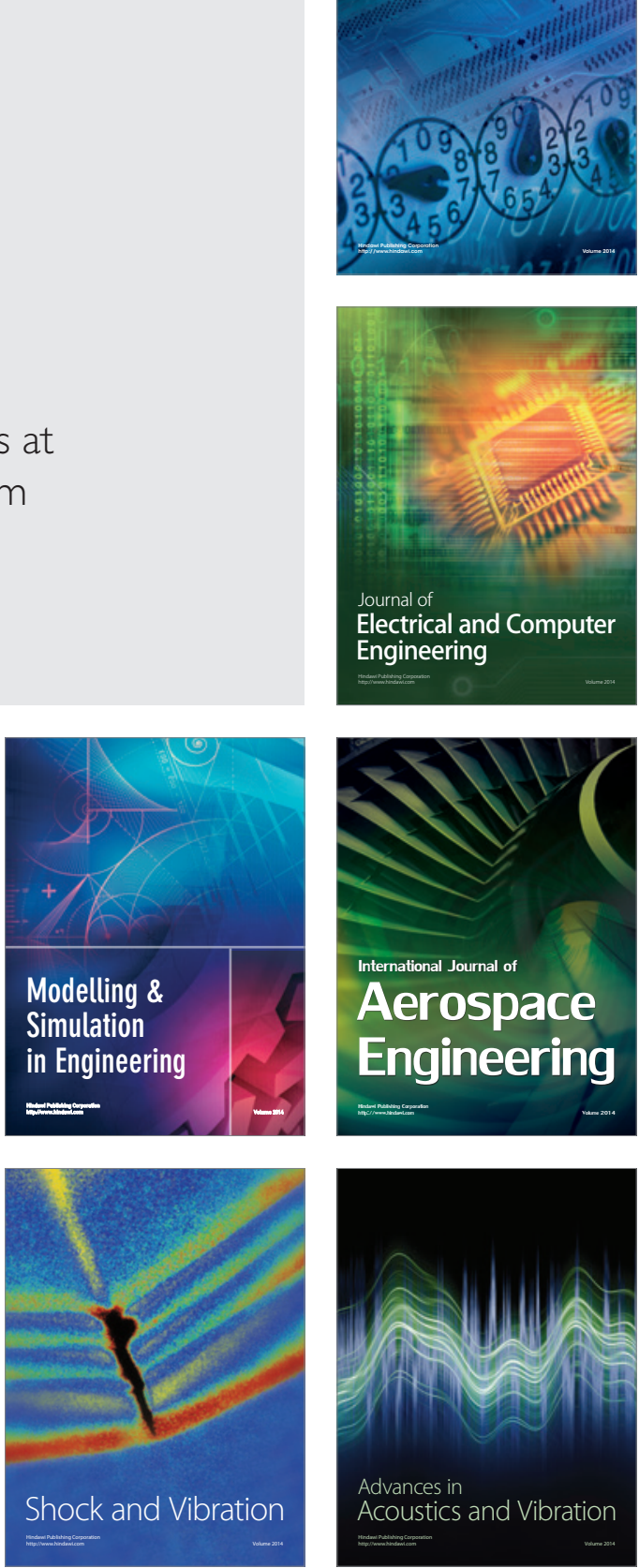